\title{
Behavior of illite and chlorite during pressure solution of shaly limestone of the Kalkberg Formation, Catskill, New York*
}

\author{
Melanie E. Kreutzberger and Donald R. Peacor
}

Department of Geological Sciences, The University of Michigan, Ann Arbor, MI 48109, U.S.A.

(Received 20 December 1986; accepted in revised form 16 June 1988)

\begin{abstract}
Textural and chemical changes occurring in illite and chlorite concomitant with pressure solution of limestone were studied in samples from the Kalkberg Formation of Catskill, New York, using XRD and TEM/AEM. Samples on one limb of an anticline are massive shaly limestones, but those on the other have undergone extensive pressure solution and well-developed cleavage is present. Illite and chlorite from the uncleaved shaly limestone are found in small individual packets $(100-800 \AA$ thick) dispersed throughout the carbonate matrix with crystal morphologies characteristic of burial diagenesis. Phyllosilicates from the limb more affected by pressure solution occur in larger units ( $>1 \mu \mathrm{m}$ thick) as stacks of subparallel packets $(150-500 \AA$ thick). Such stacks are inferred to represent coalescence of smaller packets. These data imply that the phyllosilicates are largely passive during pressure solution of limestone; however, localized solution-recrystallization is required by the coherent to semi-coherent packet boundaries and the crystal morphologies present in the pressure solution sample. The largely passive role is in contrast with the more active role of phyllosilicates in many shales and slates.

XRD data for illite show an increase in crystallinity in the pressure solution sample under isotherma conditions. Differences in illite crystallinity are adequately explained in large part by differences in crystal size with some contribution due to strain. The data demonstrate that illite crystallinity cannot be unambiguously used in determining absolute or even relative temperatures.
\end{abstract}

\section{INTRODUCTION}

Nickelsen (1972), Alvarez et al. (1976) and Mitra \& Yonkee (1985) concluded that clay minerals in limestones affected by pressure solution are an accumulation of insoluble residues; that is they have behaved as passive, insoluble minerals being concentrated by the dissolution of $\mathrm{CaCO}_{3}$. Schweitzer \& Simpson (1986) showed that in dolomite with spaced cleavage, clay minerals rotated concomitant with removal of dolomite, resulting in a preferred orientation and coalescence of the clay minerals. Yonkee et al. (1982) concluded in their study of pressure solution in micrite that phyllosilicates behave as passive, mechanically concentrated residues and as minerals undergoing recrystallization. Recrystallization or solution and crystallization of phyllosilicates has also been described in many studies of argillaceous rocks (e.g. Maxwell \& Hower 1967, Wood 1974, Holeywell \& Tullis 1975, Beach 1979, Knipe 1981, Penoyar et al. 1983, Lee et al. 1986). Using transmission and analytical electron microscopy (TEM/AEM) Lee et al. (1986) were able to document changes in composition, defect densities and textures of phyllosilicates concomitant with a solution-crystallization mechanism in the mudstone to slate transition in the Martinsburg slates at Lehigh Gap, Pennsylvania. Penoyar et al. (1983) similarly demonstrated equivalent changes in the chemical and structural state of illite in shales along the Pine Mountain Fault in northeastern Tennessee using TEM/ AEM techniques. We therefore initiated a study of

${ }^{*}$ Contribution No, 445 from the Mineralogical Laboratory, Department of Geological Sciences, The University of Michigan, Ann Arbor, MI 48109, U.S.A. phyllosilicates occurring in limestone affected by pressure solution utilizing equivalent TEM/AEM methods in order to determine whether phyllosilicates played a passive or active role during pressure solution in limestone. A well-characterized location at Catskill, New York, was chosen where solution effects have been well-defined by standard petrological methods and where a continuous sequence from unaffected to intensely affected rocks could be directly studied and sampled (Marshak 1983, Marshak \& Engelder 1985, Bhagat \& Marshak 1986).

\section{GEOLOGICAL SETTING}

The Kalkberg Formation of Catskill, New York, is part of a sequence of Lower Devonian shallow-marine limestones (Rickard 1962, Marshak \& Engelder 1985). The lime wackestone making up this formation is composed of calcite fossil fragments in a clay, quartz and calcite matrix. It is well exposed in an outcrop along Route 23, where it is folded into an anticline (the Central Anticline). The limbs of the anticline are separated by approximately $45 \mathrm{~m}$ along a continuous outcrop (Marshak \& Engelder 1985). On the southeast limb of the anticline, shaly limestone without any significant cleavage is observed. In the outcrop this limestone appears to undergo continuous change from the southeast to northwest limb, with spaced cleavage present in the intermediate samples. It approaches the appearance of a shale with well-developed cleavage in the northwest limb where it is cut by a fault. Marshak \& Engelder (1985) showed that the change in lithology is due to progressive pressure solution. Bhagat \& Marshak (1986) 
studied cleavage development using scanning electron microscopy and observed that microlithons are characterized by calcite grains that are elongated parallel to cleavage.

The samples utilized in this study were collected from both limbs of the anticline and from the same continuous bed, representing the full sequence in pressure solution. This study focuses on two of the samples-the one farthest from the fault (massive shaly limestone, apparently unaffected by pressure solution, hereafter referred to as sample NPS) and the one immediately adjacent to it (well-developed slaty cleavage, maximally affected by pressure solution, hereafter referred to as sample PS).

\section{EXPERIMENTAL METHODS AND RESULTS}

\section{$X$-ray diffraction $(X R D)$}

Powder XRD data were obtained for both the bulk rock and for the $<2 \mu$ m clay fraction size for the progressive sequence of pressure solution samples. Qualitative examination of the XRD patterns showed an increase in the intensity of the phyllosilicate peaks and a decrease in the intensity of the calcite peaks in samples increasingly affected by pressure solution. Based in part on these results, the two samples representing the end-members in the pressure solution sequence (samples NPS and PS) were singled out for detailed study.

$\mathrm{X}$-ray diffraction patterns of bulk rock samples were used to obtain average semi-quantitative weight per cents of the minerals in the two end-member samples. Concentrations were calculated utilizing integrated intensities of a given mineral relative to that of quartz, as compared with separately determined standard curves and assuming that the identified mineral per cents sum to $100 \%$. The results for sample NPS are: illite $17 \%$, chlorite $3 \%$, quartz $38 \%$, calcite $40 \%$ and albite $3 \%$; for those of sample PS: illite $21 \%$, chlorite $11 \%$, quartz $42 \%$, calcite $20 \%$ and albite $6 \%$ (weight per cents precise to approximately $\pm 25 \%$ of the amount present). The results are consistent with dissolution and removal of calcite and an increase in concentrations of the phyllosilicate minerals. Chemical analytical data were obtained by X-ray fluorescence analysis. Results included: $\mathrm{SiO}_{2}$ 39.5, 62.0; $\mathrm{CaO} 42.2,14.1 ; \mathrm{Al}_{2} \mathrm{O}_{3}$ 5.9, $12.2 ; \mathrm{Fe}_{2} \mathrm{O}_{3} 2.8,3.9 \mathrm{wt} \%$ for the NPS and PS samples, respectively. These data are qualitatively compatible with the results of Marshak \& Engelder (1985) whose bulk chemical analyses of the Kalkberg Formation show a smaller decrease in $\mathrm{CaCO}_{3}$ and an increase in $\mathrm{K}_{2} \mathrm{O}$, $\mathrm{Al}_{2} \mathrm{O}_{3}$ and $\mathrm{SiO}_{2}$, indicating that calcite had been removed.

The $<2 \mu \mathrm{m}$ clay fraction was concentrated by gravity settling and then placed on ceramic tiles in order to optimize XRD patterns of the clay minerals. The halfheight width of the 001 peak of illite (Kubler 1968) was determined as an average of nine (sample PS) and 10 (sample NPS) measurements and found to decrease from $0.47 \pm 0.04^{\circ} \Delta 2 \theta$ in the NPS limestone to $0.37 \pm$ $0.02^{\circ} \Delta 2 \theta$ in the PS sample. No comparisons were made with standard samples so only the relative difference in $2 \theta$ has quantitative significance. The characteristic asymmetry of the illite peak is also less in sample PS. Marshak \& Engelder (1985) observed a similar difference in peak width.

\section{Hand samples, optical study and scanning electron microscopy (SEM)}

In hand specimen, samples NPS and PS displayed distinct differences, including the lack of cleavage development in NPS contrasting with the almost slaty appearance of sample PS. In sample PS, there are many lenses $(0.1-15 \mathrm{~mm}$ wide) of calcite cutting through the rock, not observed in sample NPS. These lenses could be the result of local redeposition of calcite after pressure solution.

Individual grains could generally not be resolved optically using standard thin sections, although some fossil fragments and a few larger quartz and calcite grains were observed. A Hitachi SEM with back-scattered electron (BSE) and energy dispersive analysis (EDA) detectors was therefore utilized to examine the textural relationships and the minerals present. Sample NPS shows grains of calcite, quartz, fossil fragments, and occasional pyrite, magnetite, $\mathrm{TiO}_{2}$ (rutile?) and zircon homogeneously scattered throughout the sample. Figures 1(a) $\&$ (b) display the typical texture, showing calcite and quartz homogeneously distributed without preferred orientation or shape. In other areas, calcite in the form of fossil fragments is more abundant. Larger grains of calcite and quartz are also observed in some areas of the sample. Small domains of phyllosilicates are present as light grey elongated areas, although their apparent width is exaggerated as an artifact of the ion milling process. Only a single large detrital grain displays its true size in Figs. 1(a) \& (b). We emphasize that most of the illite and chlorite grains (inferred to be authigenic) are too small to be resolved in such BSE images. The grains that can be observed are inferred to be the larger, detrital grains. Sample PS (Figs. 1c \& d) shows the same minerals, but they are concentrated in elongated larger areas, rather than being scattered homogeneously throughout the sample. There is very little calcite in the section, presumably due to dissolution due to pressure solution. Grains of quartz are elongated parallel to the cleavage direction implying dissolution and crystallization of those grains. The elongated quartz grains contain inclusions of calcite. Growth of quartz around calcite apparently armored it against dissolution. The clay domains are significantly larger and thus more readily observed. They are preferentially aligned parallel to elongated domains of quartz, parallel to cleavage. Clay minerals occupy a significant proportion of the figure, although the individual grains cannot be resolved at $\mathrm{BSE}$ resolution.

SEM observations were also made on an intermediate sample with spaced cleavage. Cleavage domains and incipient cleavage domains are characterized by a concentration of phyllosilicates with (001) parallel to the 

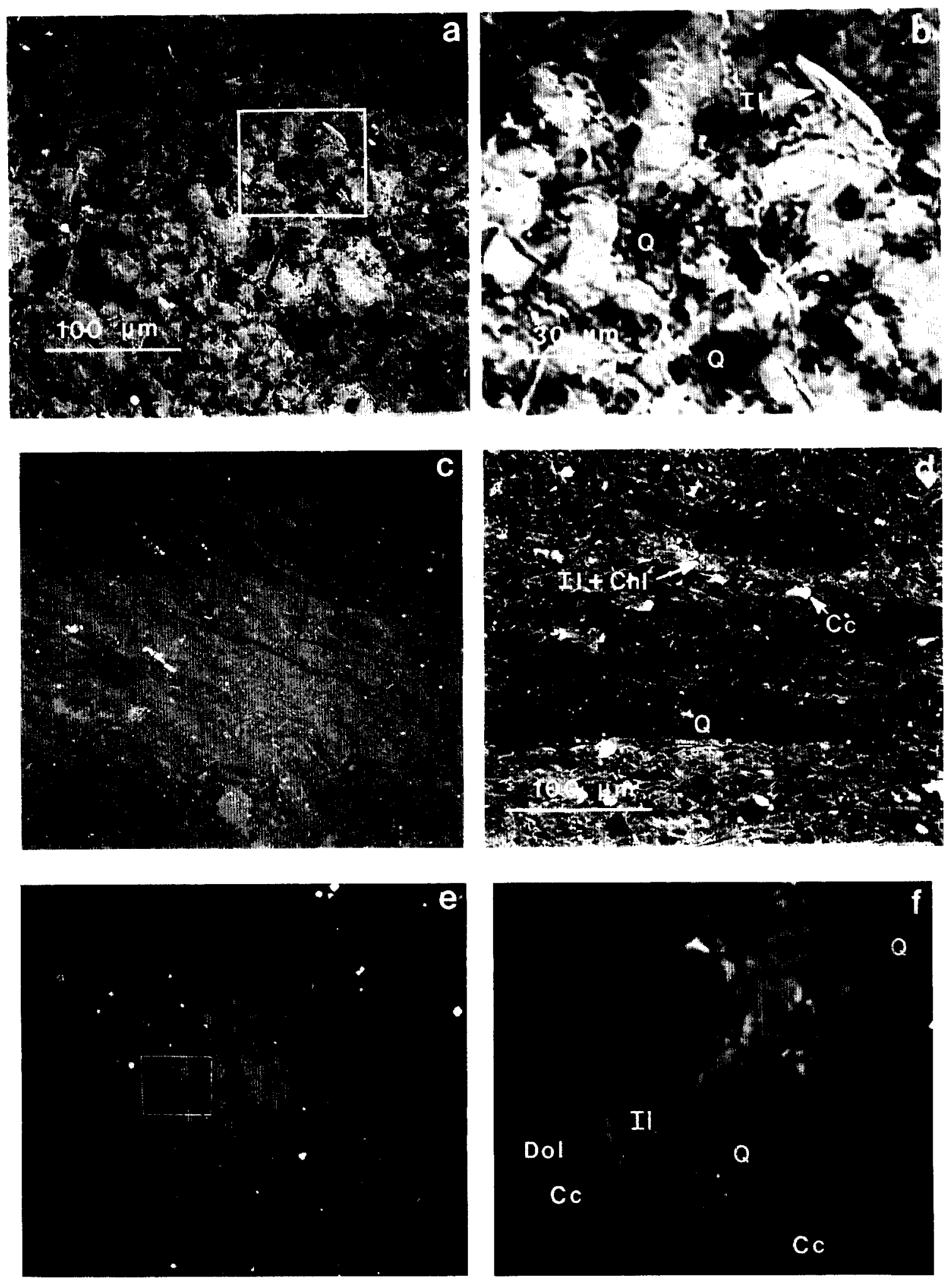

Fig. 1. (a) and (b) SEM BSE images of the sample not affected by pressure solution, sample NPS. The image is of an ion-milled surface of the sample used for STEM observations of Figs. 2(a)-(c). (a) Image of texture free of fossil fragments. Calcite and quartz are regularly distributed without preferred orientation. (b) High-magnification image showing phyllosilicates that are inferred to be detrital in origin. The ion-milling process causes the clay mineral grains to appear to be thicker than they are. Most of the clay mineral grains cannot be resolved in these images. Light grey = calcite; dark grey = quartz; bright areas = pyrite and oxides. $\mathrm{Cc}=$ calcite; $\mathrm{Q}=$ quartz; $\mathrm{Il}=\mathrm{illite} ; \mathrm{Chl}=$ chlorite; Dol = dolomite. (c) and (d) SEM BSE images of the sample affected by pressure solution, sample PS. The images are of an ion-milled surface of a sample used for the STEM observations of Figs. 2(b), (e) \& (f). (c) Image shows elongation of grains due to dissolution and crystallization. Only a small amount of calcite remains. (d) Higher magnification image showing phyllosilicates. Note elongation of mineral grains. Mineral legends as in (b). (e) and (f) SEM BSE images of a polished thin section of an intermediate sample with spaced cleavage. (e) Image showing two cleavage domains with concentrations of phyllosilicates. Illite and chlorite grains are aligned parallel to the cleavage. Quartz and carbonate grains are elongated parallel to the cleavage. due to dissolution and crystallization. The proportion of calcite is reduced along the incipient cleavage.

(f) Enlarged image of this area. Minerals as in (b). 


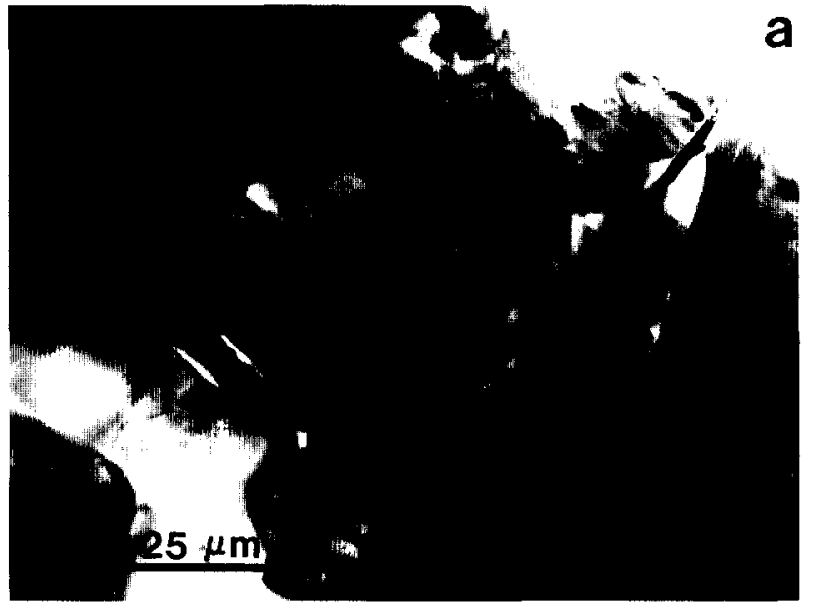

a b
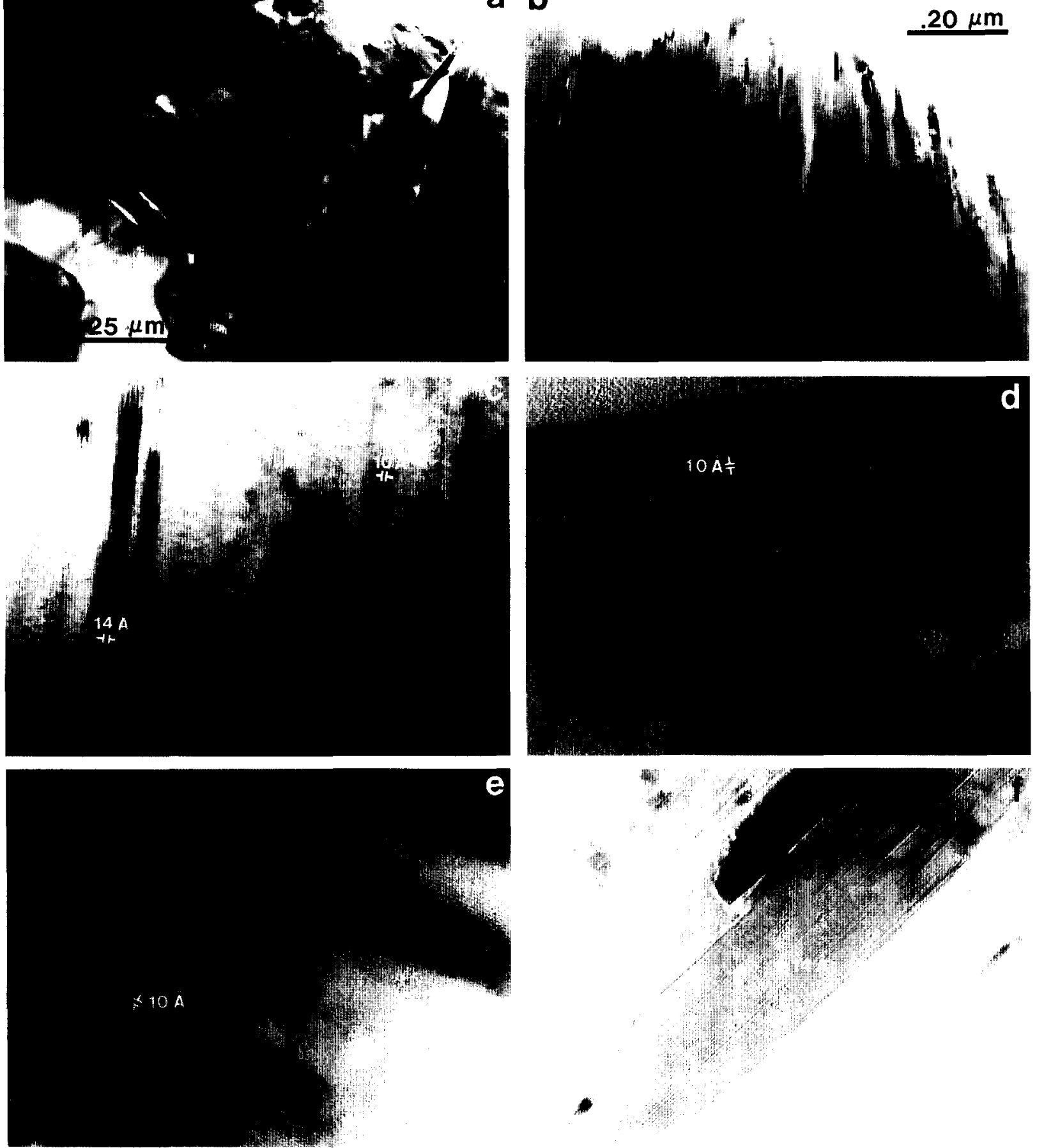

Fig. 2. (a) TEM image of the typical texture of sample NPS, showing small illite packets $180-820 \AA$ An thickness in a matrix of quartz and calcite. (b) TEM image of a typical stack of illite packets in sample PS; area represented is about $1 u \mathrm{~m}^{2}$ (c) TEM image of sample NPS; lattice fringe images of adjacent illite and chlorite packets. (d) TEM image of sample NPS; packets of illite layers (60-500 $\AA$ thick) in a matrix of calcite. Packets are curved and have irregular edges. (e) TEM image of sample PS; lattice fringe image of illite grain showing low-angle grain boundaries between packets. (f) TEM image of sample PS; chlorite grain ( $660 \AA-0.1 \mu \mathrm{m}$ thick). A chlorite packet has a sharply stepped termination. 
cleavage and by an elongation of quartz and calcite adjacent to the phyllosilicates (Figs. 1e \& f). Elongation of calcite grains was also described by Bhagat \& Marshak (1986) in similar samples. Calcite grains were also observed to have been cut by selvages, and show displacement and lack of fit across them. Dolomite having calcite rims and an anhedral shape occurs adjacent to the selvages. Similar zoning was observed in a few grains in sample PS, but not in sample NPS and it is therefore assumed to be related to the pressure solution process. Even at higher magnifications illite and chlorite could usually not be distinguished, presumably due to having grain sizes below resolution by SEM.

\section{Transmission electron microscopy (TEM)}

TEM observations were made using a JEOL JEM100CX Scanning Transmission Electron Microscope (STEM). Samples were obtained from thin sections oriented perpendicular to the cleavage, and representative areas were chosen for TEM observations following optical and SEM observations. Methods of study are described by Lee et al. (1986).

Figures 2(a) \& (b) show representative textures of end-member samples as seen in low-resolution TEM images. Sample NPS contains phyllosilicates, illite in this case, occurring in small (100-800 $\AA$ thick) individual, curving packets, randomly scattered among calcite and quartz grains without preferred orientation (Fig. 2a). The thickness of the phyllosilicates is measured parallel to $c^{*}$. The phyllosilicates are easily differentiated from other minerals by their crystal morphologies (thin, elongate) and electron diffraction patterns. Quartz and calcite are also identified by their crystal shapes and electron diffraction patterns. Illite is distinguished from chlorite by a characteristic 'mottling' effect due to damage from the electron beam which is not observed in chlorite, and by the spacing of the lattice fringes obtained using $\{001\}$ diffraction patterns (illite: $10 \AA$; chlorite: $14 \AA$ ).

Figure $2(b)$ is an image of sample PS showing illite occupying an area approximately $1 \mu \mathrm{m}$ wide. This area is made up of phyllosilicates found in parallel or nearparallel individual packets of layers $150-500 \AA$ thick. Within an individual packet, structure is continuous, homogeneous and nearly defect-free. The boundaries between packets resemble low-angle grain boundaries; they are semi-coherent in that some layers from one packet terminate against the limiting layer of adjacent packets, while others are continuous where adjacent packets consist of the same mineral. The sequence of individual packets of illite and chlorite thus alternate to collectively form large, continuous, heterogeneous crystals. Such phyllosilicate crystals occur in distinct domains, not dispersed throughout a matrix of calcite and quartz as in sample NPS.

The long dimensions of the phyllosilicate grains in the 2D TEM images of sample PS appear to be larger than those of sample NPS. The widths of the grains in 20 TEM images from each sample were therefore measured and averaged. The widths are the apparent diameter as projected onto the 2D TEM image. The average width of grains in sample NPS is approximately $0.63 \pm 0.48 \mu \mathrm{m}$ while that in sample PS is $0.99 \pm 0.76 \mu \mathrm{m}$, although grain dimensions range from a few hundred Ångstroms to several microns in both samples. The difference in values is not statistically significant, especially when the small areas ( $3 \mathrm{~mm}$ diameter) represented by TEM specimens are considered. This implies that there is little, if any, difference in grain width.

In both samples chlorite and illite can be found adjacent to one another and as separate grains. Figures 2 (c) $\&$ (d) are from sample NPS. Figure 2(c) is a lattice fringe image showing the difference in fringe spacings of adjacent illite $(10 \AA)$ and chlorite $(14 \AA)$. Figure $2(\mathrm{~d})$ is an image of several packets of illite $60-500 \AA$ in thickness dispersed throughout a carbonate matrix. This is the characteristic texture of the illite in the shaly limestone not affected by pressure solution. Such packets are often characterized by slight curvature. In addition, although they are generally defined by sharp $\{001\}$ surfaces, the ends of the packets are usually irregular and serrated.

Figures 2(e) \& (f) are from sample PS showing textural features at high resolution. The characteristic texture of illite in this sample is seen in Fig. 2(e). It illustrates the typical subparallel packets with semi-coherent to coherent boundaries. It appears that such boundaries are produced by coalescence of separate packets; this, therefore, requires that some solution-recrystallization occurred at the boundaries. A $20 \AA$ periodicity, as consistent with a two-layer polytype, can also be observed in some of the illite packets from this image (see paragraph below for data on polytypes). The illite from sample NPS (Fig. 2d) occurs in small curved packets, compared to the illite of sample PS which is characterized by straight, relatively defect-free fringes. The $10 \AA$ lattice spacing of a representative illite can be observed in Fig. 2(e). The 'mottling' feature of illite is readily observed in this image. Figure $2(\mathrm{f})$ is representative of chlorite from the pressure solution sample. The chlorite grains from both end-member samples are quite similar in their defect-free appearance, although they do differ in their crystal morphologies. A chlorite grain from sample PS shows a step-like termination along one edge of its boundary (Fig. 2f). This feature, observed only in sample NPS, may be characteristic of crystallization of phyllosilicate grains from solution as will be discussed below.

\section{Polytypism}

Characterization of illite polytypes was derived from selected area diffraction (SAD) patterns where crystal orientation allowed observation of appropriate non-001 reflections. The polytype found in both of the endmember samples has $20 \AA$ periodicity, implying that the predominant polytype is $2 \mathrm{M}_{1}$, the common two-layer polytype of white micas. No other polytype was observed. Some streaking was observed along $c^{*}$, sug- 
gesting the presence of limited stacking disorder. Such streaking was always weak in intensity and no differences could be discerned between the two end-member samples.

\section{Analytical electron microscopy (AEM)}

Because individual phyllosilicate grains were too small for analysis using the electron microprobe, AEM analyses were obtained, utilizing an EDA system and methods described in Ahn \& Peacor (1985). Electron transparent edges (500-1000 $\AA$ thick) were analyzed using grains that were first characterized using TEM techniques. The ratios of cation peak intensities to those of silica were corrected by using proportionality constants ( $k$-values) determined from standards. Gotthard adularia was used as a standard for $\mathrm{K}$ and $\mathrm{Al}$, clinochlore for $\mathrm{Mg}$ and $\mathrm{Fe}$. Due to the small sizes of the grains being analyzed, there was significant overlap of adjacent mineral grains; this effect was more prominent with the smaller NPS grains. Analyses that included $\mathrm{Ca}$, presumably due to the presence of calcite, were disregarded in both samples, as were analyses that included $\mathrm{Si}$, due to quartz. The overlap effects in the larger grains of sample PS were more subtle and difficult to detect; therefore some contamination from adjacent minerals may still be present.

Normalized compositions were based on six octahedral + tetrahedral cations for illite and 10 for chlorite. Averages for the compositions of illite and chlorite were determined (Table 1).

For sample NPS the compositions are:

illite

$$
\mathrm{K}_{0.6}\left(\mathrm{Al}_{1.7} \mathrm{Fe}_{0.2} \mathrm{Mg}_{0.2}\right)\left(\mathrm{Si}_{3.4} \mathrm{Al}_{0.6}\right) \mathrm{O}_{10}(\mathrm{OH})_{2}
$$

chlorite

$$
\left(\mathrm{Mg}_{2.1} \mathrm{Fe}_{2.7} \mathrm{Al}_{1.2}\right)\left(\mathrm{Si}_{2.6} \mathrm{Al}_{1.4}\right) \mathrm{O}_{10}(\mathrm{OH})_{8}
$$

For sample PS:

illite

$$
\mathrm{K}_{0.5}\left(\mathrm{Al}_{1.6} \mathrm{Fe}_{0.2} \mathrm{Mg}_{0.2}\right)\left(\mathrm{Si}_{3.5} \mathrm{Al}_{0.5}\right) \mathrm{O}_{10}(\mathrm{OH})_{2}
$$

chlorite

$$
\left(\mathrm{Mg}_{2.9} \mathrm{Fe}_{1.9} \mathrm{Al}_{1.2}\right)\left(\mathrm{Si}_{3.0} \mathrm{Al}_{1.0}\right) \mathrm{O}_{10}(\mathrm{OH})_{8}
$$

The compositions of illite from the two samples are equal within standard error of analysis. The formulae for illite suffer from a deficiency of positive charge ( -0.1 for sample NPS; -0.4 for sample PS). This can be accounted for, in part, by the presence of $\mathrm{Fe}^{3+}$ rather than $\mathrm{Fe}^{2+}$. In addition, AEM analyses in illite generally give values that are too low due to diffusion of $K$ during analysis (Lee, personal communication), even when great care is used. The true values for $\mathrm{K}$ may be as high as 0.7 or 0.8 , further accounting for the charge deficiency. The Fe and $\mathrm{Mg}$ components are typical of other illites (Ahn et al. 1985). It is generally agreed that illite derived from smectite has a limiting composition of approximately 0.5 $\mathrm{K}$ per formula, with a tetrahedral occupancy of $\mathrm{Si}_{3.5} \mathrm{Al}_{0.5}$
Table 1. Normalized analytical electron microscopy data for illite and

\begin{tabular}{|c|c|c|}
\hline & NPS ( 19 grains -74 analyses) & PS (33 grains -107 analyses) \\
\hline $\mathbf{K}$ & 0.6 & 0.5 \\
\hline $\mathrm{Si}$ & 3.4 & 3.5 \\
\hline $\mathrm{Al}(\mathrm{IV})$ & 0.6 & 0.5 \\
\hline $\mathrm{Al}(\mathrm{VI})$ & 1.7 & 1.6 \\
\hline $\mathrm{Fe}^{*}$ & 0.2 & 0.2 \\
\hline \multirow[t]{3}{*}{$\mathrm{Mg}$} & 0.2 & 0.2 \\
\hline & \multicolumn{2}{|c|}{$\begin{array}{c}\text { Chlorite } \\
\text { atoms: } 10(\mathrm{IV}+\mathrm{VI}) \text { cations }\end{array}$} \\
\hline & NPS (8 grains-18 analyses) & PS ( 2 grains -2 analyses) \\
\hline $\mathrm{Si}$ & 2.6 & 3.0 \\
\hline $\mathrm{Al}(\mathrm{IV})$ & 1.2 & 1.0 \\
\hline $\mathrm{Al}(\mathrm{VI})$ & 1.4 & 1.2 \\
\hline $\mathrm{Fe}^{*}$ & 2.7 & 1.9 \\
\hline $\mathrm{Mg}$ & 2.1 & 2.9 \\
\hline
\end{tabular}
chlorite from samples NPS and PS

Illite

atoms: $6(\mathrm{IV}+\mathrm{VI})$ cations

*Total $\mathrm{Fe}\left(\mathrm{Fe}^{2+}\right.$ and $\left.\mathrm{Fe}^{3+}\right)$

(Środón \& Eberl 1984). Lee et al. (1986) contend that the composition of illite changes continuously toward that of muscovite with increasing degree of diagenesis or grade of metamorphism. However, assuming that $\mathrm{K}$ contents are slightly low in both samples, both the compositions are consistent with partial transition toward muscovite.

On the other hand, the chlorite in sample PS is richer in $\mathrm{Mg}$ and $\mathrm{Si}$ and poorer in $\mathrm{Fe}$ and $\mathrm{Al}$ than the chlorite in sample NPS. This is consistent with the observation of Knipe (1979) that the Fe content of chlorites decreases in samples undergoing solution and crystallization during cleavage formation in slates. The difference in the composition of the chlorite from the two samples should not be taken as definitive, however, since only two analyses are used for the average in sample PS. More were obtained, but could not be used due to the overlap problem with quartz and illite as mentioned above. The overlap onto these minerals may also be the reason for the excess in positive charge in the average chlorite composition $(+0.2)$ of sample PS.

\section{DISCUSSION}

\section{Illite crystallinity}

The decrease in the half-height width of the 001 peak of illite from samples of this study $(0.47+\Delta 2 \theta$ in NPS to $0.37^{\circ} \Delta 2 \theta$ in PS) indicates that the illite has undergone change, increasing in 'index' of crystallinity. Decreasing peak width and asymmetry have been attributed to several factors including a decrease in number of intercalated expandable smectite layers (e.g. Kubler 1968, Dunoyer de Segonzac 1970, Frey et al. 1980, Kisch 1980a,b, Weaver \& Broekstra 1984), but may also be due to a decrease in the density of structural defects and 
an increase in crystallite size. Marshak \& Engelder (1985) suggested similar reasons for the decrease in the illite peak width in samples from the Kalkberg Formation. However, no direct observations of such features in relation to illite crystallinity have ever been made and their effects remain untested.

Intercalation of remnant layers of smectite with interplanar spacings greater than those of illite is the most commonly used explanation of asymmetry and increased peak width in illite diffraction patterns. There is no evidence for intercalated layers of smectite or other phases in these TEM images of samples, using the criteria of Ahn \& Peacor (1986) to differentiate illite and smectite layers. However, there is some ambiguity in differentiating individual illite and smectite layers, so the conclusion that smectite layers do not exist is a qualified one. A much more likely source of variation in layer spacing exists, in that illite is recognized to be a heterogeneous phase. Variation in factors such as $\mathrm{Al} / \mathrm{Si}$ ratio, proportion of interlayer sites filled by $\mathrm{K}$, and presence of interlayer $\mathrm{H}_{2} \mathrm{O}$ (or $\mathrm{H}_{3} \mathrm{O}^{+}$) must cause local variation in spacing and therefore increase in peak width. Such minor fluctuations in lattice fringe spacing are not detectable with the present TEM methods.

On the other hand, there is a significant increase in the size of composite crystals in sample PS relative to sample NPS. The Scherrer equation is commonly used as an approximation to the relation between crystallite size and broadening of XRD reflections (Cullity 1956). The breadth of the 001 reflections is a function only of thickness of crystals parallel to [001]. Approximate thickness values of $450 \AA$ for sample NPS and $10,000 \AA$ $(1 \mu \mathrm{m})$ for sample PS were used in the Scherrer equation, resulting in contributions to peak breadth of 0.18 and $0.01^{\circ}$, respectively. The effect of crystallite size is thus greater than the observed difference in half-height widths $\left(0.12^{\circ} 2 \theta\right)$ and is therefore sufficient to account for the changes in crystallinity.

Other well-recognized causes of peak broadening include various structural defects such as dislocations (layer terminations in clay minerals) and non-uniform strain as present in curved crystals. Lee et al. (1985) have documented the general decrease in dislocations with increasing degree of diagenesis, but the samples in this study display no apparent difference in this regard. On the other hand, curvature of layers in sample NPS is common (Fig. 2d), but layers of illite packets in sample PS show little curvature, and this could partially explain the decrease in width of XRD peaks (Cullity 1956).

Illite crystallinity has been shown, in many cases, to be correlated to grade of diagenesis or metamorphism (e.g. Kubler 1968, Foscolos \& Kodama 1974, Kisch 1980a,b). Many authors have attempted to calibrate illite crystallinity quantitatively to a temperature scale. For example, Mitra \& Yonkee (1985) have used illite crystallinity in order to determine specific temperatures. Others (e.g. Peacor et al. 1986) have noted that increases in illite peak breadths are related to kinetic factors, only one of which is temperature, and that illite crystallinity cannot be accurately correlated with temperature alone.
The samples of this study underwent progressive pressure solution with changes in crystallinity under isothermal conditions. Such changes cannot therefore be correlated with temperature. On the other hand, water may serve as a mediator of chemical reactions and its effect, at least in this case, is significant. Great care should be used in interpreting the significance of changes in illite crystallinity and especially in using such changes to estimate both absolute and relative temperatures.

\section{The role of phyllosilicates in limestone pressure solution}

The limestone of the Kalkberg Formation has undergone pressure solution with loss of a significant proportion of the original calcite. As shown by the SEM and TEM images, there is a distinct difference in the textures of the phyllosilicate minerals in the two end-member samples; chlorite and illite occur in larger ( $1 \mu \mathrm{m}$ thick) subparallel packets in sample PS while in sample NPS they occur in small (100-800 $\AA$ ), individual, randomly oriented packets. However, the large grains in sample PS can be resolved into individual packets which have, to a first approximation, the same widths and thicknesses as the individual packets in sample NPS. These observations indicate that the large grains in sample PS may represent the rearranged and coalesced individual grains in sample NPS. To that degree the individual packets were unchanged. Gray (1981) and Schweitzer \& Simpson (1986) showed similar coalescence in their studies of argillaceous limestone and dolomite, respectively. On the other hand, the boundaries between the packets are semi-coherent to coherent, indicating that there must have been some solution-recrystallization along the boundaries. Statistically, there is no measurable difference in the diameters of the tabular phyllosilicate grains, implying that little or no new crystal growth occurred in that dimension.

Solution-crystallization or recrystallization can give rise to changes in composition in illite and chlorite (Knipe 1979, Lee \& Peacor 1985). When $\mathrm{K}$ and $\mathrm{Al}$ are available in solution, illite should exhibit an increase in both $\mathrm{K}$ and $\mathrm{Al}$ and a decrease in $\mathrm{Si}$ as it approaches the ideal muscovite composition representative of higher grade. No such variation in composition was observed in this study. As $\mathrm{K}$-feldspar is the generally accepted source for $\mathrm{K}$ and $\mathrm{Al}$ (Hower et al. 1976, Hoffman \& Hower 1979), and as it was not detected in this study, the lack of change in composition of illite may simply be due to lack of the necessary components and may not imply a passive role for it. More probable is the possibility that no chemical change occurred and that little dissolution of illite occurred. There may be some solution-crystallization or a recrystallization component as suggested by the chlorite compositions, but this is not yet substantiated.

Illite polytypism has been shown to progress through the sequence $1 \mathrm{M}_{\mathrm{d}} \rightarrow 1 \mathrm{M} \rightarrow 2 \mathrm{M}$ with increase in grade of diagenesis and metamorphism (e.g. Yoder \& Eugster 1955, Maxwell \& Hower 1967, Hunziker et al. 1986) as solution-crystallization or recrystallization of illite occurs. Both end-member samples of this study consist 
primarily of a two-layer polytype (most likely $2 \mathrm{M}_{1}$ ), indicating that illite attained the limiting polytype before pressure solution occurred. The state of polytypism therefore provides no evidence for solution and crystallization or recrystallization, nor the absence of such processes in these specimens. It must be emphasized that this is a troublesome aspect of this study, as changes in polytypism are among the easiest of all changes to detect during prograde metamorphism. Additional studies where $1 \mathrm{M}$ or $1 \mathrm{M}_{\mathrm{d}}$ polytypes occur in NPS-like samples are certainly desirable.

The TEM images of the phyllosilicates of the two samples show distinctly different textures and crystal morphologies. Similar textures have been associated with very different origins in other studies. Crystals from the NPS sample are similar to phyllosilicates observed by Lee et al. (1985) and Ahn \& Peacor (1986) in Gulf Coast sediments $\rightarrow$ small and curved with contacts between the phyllosilicate domains and the surrounding matrix displaying irregular boundary features. The similarities are especially striking in the serrated terminations of crystals in sample NPS. In the case of Gulf Coast samples, the clay mineral domains represent original detrital minerals (usually smectite) that have undergone diagenesis in part or in whole to other clay minerals (usually chlorite or illite). The process is one of progressive replacement rather than solution and crystallization of entire grains.

In contrast, the surfaces of phyllosilicates in the PS sample show a step-like crystal morphology, especially at their ends (Fig. 2f) and display no curvature. Such crystal morphologies were observed by Yau \& Peacor (1987) and Yau et al. (in press) in samples from the Salton Sea area where phyllosilicates have undergone hydrothermal crystallization, and by Yau et al. (1987) in illite and chlorite that were hydrothermally grown in laboratory experiments following dissolution of other starting phases. These and other textural features were ascribed to solution of pre-existing phases (primarily smectite), and crystallization at a site separate from the original detrital phases. The common occurrence of similar features in sample PS suggests that some solution and crystallization may have affected crystal surfaces and terminations. This reasoning utilizes qualitative interpretations of textures from the sources noted above, to which reference should be made for a firmer sense of the differences in textures.

Although some solution and crystallization or recrystallization apparently occurred locally at packet surfaces, the phyllosilicates apparently were largely unchanged. This is in contrast with phyllosilicates in shales and slates which may undergo major solution and crystallization at the same metamorphic grade (e.g. Lee et al. 1986). In carbonate-rich rocks the clay minerals are found in low proportions scattered throughout the matrix. An important mechanism during deformation of calcite/dolomite rocks is twin gliding. In general, the resulting strained, defect-rich domains are more susceptible to solution (Wenk et al. 1983), and the carbonates composing most of the rock are considerably more soluble than the dispersed phyllosilicates. Indeed, pressure solution may be enhanced by the presence of phyllosilicates, with pathways along carbonate-phyllosilicate grain boundaries promoting fluid transport (e.g. Weyl 1959, De Boer 1977, Marshak \& Engelder 1985, Schweitzer \& Simpson 1986). Phyllosilicates may therefore be considered largely as unchanging markers in a carbonate matrix. As matrix carbonates are removed by solution, the phyllosilicates may rotate until their long dimension is perpendicular to the maximum principal compressive stress (Oertel 1983). On the other hand, in shales and slates there is a significantly higher proportion of phyllosilicates. Deformation, in part, occurs through grain to grain contacts between phyllosilicates. Furthermore, shales and slates have significant amounts of competent quartz and albite that are less soluble than calcite. Contacts of phyllosilicates with quartz or albite result in enhanced solution of phyllosilicates compared with those in contact with carbonates (Oertel 1983). Rotation without dissolution similar to that found in carbonate-rich rocks may occur at the onset of deformation, followed by solution and crystallization or recrystallization of the phyllosilicates as the principal response to stress (e.g. Knipe 1979, 1981, Lee et al. 1986). It therefore appears that the role of phyllosilicates in carbonate-rich rocks compared to their role in shales and slates is a function of the differences in phyllosilicate concentrations, the relative solubilities of the minerals present, and the response of the matrix minerals to stress.

\section{CONCLUSIONS}

(1) There is a well-defined increase in illite crystallinity concomitant with pressure solution in the samples of this study. There are no differences in polytypism and average composition between samples, but the differences in crystallite size adequately account for variation in crystallinity, as augmented by lattice strain.

(2) Changes in illite crystallinity occurred under isothermal conditions, implying that such changes relate to kinetic factors, only one of which is temperature. Fluids taking part in pressure solution apparently promoted changes in crystallinity. Absolute temperatures cannot, in general, be independently determined using illite crystallinity alone.

(3) The collective TEM results imply that the phyllosilicates in the limestone of the Kalkberg Formation have not undergone significant dissolution and crystallization during pressure solution. The individual crystal packets coalesced after removal of calcite to form large crystals of subparallel packets. There seems to have been at least some partial solution and crystallization involving the surfaces of the illite and chlorite grains in the PS sample. However, the overall textural relations imply that the packets retained their identity during the pressure solution process.

Acknowledgements-We are grateful to Dr S. Marshak for help in the 
preliminary stages of this study, especially with respect to sampling suggestions, for providing unpublished data and for reviewing the manuscript. We are thankful to Drs B. A. van der Pluijm, R. P. Wintsch, E. J. Essene and D. V. Wiltschko for reviews and suggestions. Especial appreciation is extended to A. Afifi and Dr R. Arculus for providing $\mathrm{X}$-ray fluorescence analytical data. We wish to thank the staff of the University of Michigan Electron Microbeam Analysis Laboratory for their assistance. We also thank Drs Jung Ho Ahn and Lancy Yu-Chyi Yau for their generous help. The analytical STEM used in this work was acquired under Grant DMR-77-09643 and the SEM under Grant BSR-83-14092 from the National Science Foundation. The study was supported by NSF Grants EAR-8604170 and EAR-8313236 to D. R. Peacor

\section{REFERENCES}

Ahn, J. H. \& Peacor, D. R. 1985. Transmission electron microscopic study of diagenetic chlorite in Gulf Coast argillaceous sediments. Clays Clay Miner. 33, 228-236.

Ahn, J. H. \& Peacor, D. R. 1986. Transmission and analytical electron microscopy of the smectite-to-illite transition. Clays Clay Miner. 34, 165-179

Ahn, J. H., Peacor, D. R. \& Essene, E. J. 1985. Coexisting paragonite-phengite in blueschist eclogite: a TEM study. Am. Miner. 70, 1192-1204.

Alvarez, W., Engelder, T. \& Lowrie, W. 1976. Formation of spaced cleavage and folds in brittle limestone by dissolution. Geology 4 , 698-701.

Beach, A. 1979. Pressure solution as a metamorphic process in deformed terrigenous sedimentary rocks. Lithos 12, 51-58.

Bhagat, S. \& Marshak, S. 1986. Cleavage-parallel extension fabrics in limestone from a fold-thrust belt (abstr.). Geol. Soc. Am. Abs. w. Prog. 18, 540 .

Cullity, B. D. 1956. Elements of X-ray Diffraction. Addison-Wesley, Reading, Massachusetts.

De Boer, R. B. 1977. On the thermodynamics of pressure solutioninteraction between chemical and mechanical forces. Geochim. cosmochim. Acta 41, 249-256.

Dunoyer de Segonzac, G. 1970. The transformation of clay minerals during diagenesis and low-grade metamorphism: a review. Sedimentology 15, 281-346.

Foscolos, A. E. \& Kodama, H. 1974. Diagenesis of clay minerals from lower Cretaceous shales of north eastern British Columbia. Clays Clay Miner. 22, 319-335.

Frey, M., Teichmüller, M., Teichmüller, R., Mullis, J. Künzi, B., Breitschmid, A., Gruner, U. \& Schwizer, B. 1980. Very low-grade metamorphism in external parts of the central Alps: Illite crystallinity, coal rank and fluid inclusion data. Eclog. geol. Helv. 73, 173-203.

Gray, D. R. 1981. Compound tectonic fabrics in singly folded rocks from southwest Virginia, U.S.A. Tectonophysics 78, 229-248.

Hoffman, J. \& Hower, J. 1979. Clay mineral assemblages as low grade metamorphic geothermometers: application to the thrust faulted disturbed belt of Montana, U.S.A. In: Aspects of Diagenesis (edited by Scholle, P. A. \& Schluger, P. R.). Spec. Publs. Soc, econ. Paleont. Miner. 26, 55-59.

Holeywell, R. C. \& Tullis, T. E. 1975. Mineral reorientation and slaty cleavage in the Martinsburg Formation, Lehigh Gap, Pennsylvania. Bull. geol. Soc. Am. 86, 1296-1304.

Hower, J., Eslinger, E. V., Hower, M. E. \& Perry, E. A. 1976. Mechanism of burial metamorphism of argillaceous sediment: 1 . Mineralogical and chemical evidence. Bull. geol. Soc. Am. 87, 725-737.

Hunziker, J. C., Frey, M., Clauer, N., Dallmeyer, R. D., Friedrichsen, H., Flehmig, W., Hochstrasser, K., Roggwiler, P. \& Schwander, H. 1986. The evolution of illite to muscovite: mineralogical and isotopic data from the Glarus Alps, Switzerland. Contr. Miner. Petrol. 92, 157-180.

Kisch, H. J. 1980a. Illite crystallinity and coal rank associated with lowest-grade metamorphism of the Taveyanne greywacke in the Helvetic zone of the Swiss Alps. Eclog. geol. Helv. 73, 753-777.

Kisch, H. J. 1980b. Incipient metamorphism of Cambro-Silurian clastic rocks from the Jämtland Supergroup, Central Scandinavian Caledonides, western Sweden: illite crystallinity and 'vitrinite' reflectance. J. geol. Soc. Lond. 137, 271-288.
Knipe, R. J. 1979. Chemical changes during slaty cleavage development. Bull. Minéral. 102, 206-209.

Knipe, R. J. 1981. The interaction of deformation and metamorphism in slates. Tectonophysics 78, 249-272.

Kubler, B. 1968. Evaluation quantitative du métamorphisme par la cristallinité de l'illite. Bull. Cent. Rech. Pau-SNPA 2, 385-397.

Lee, J. H., Ahn, J. H. \& Peacor, D. R. 1985. Textures in layered silicates: progressive changes through diagenesis and low-temperature metamorphism. J. sedim. Petrol. 55, 532-540.

Lee, J. H. \& Peacor, D. R. 1985. Ordered 1:1 interstratification of illite and chlorite: a transmission and analytical electron microscopy study. Clays Clay Miner. 33, 463-467.

Lee, J. H., Peacor, D. R., Lewis, D. D. \& Wintsch, R. P. 1986. Evidence for syntectonic crystallization for the mudstone to slate transition at Lehigh Gap, Pennsylvania.J. Struct. Geol. 8, 767-780.

Marshak, S. 1983. Aspects of deformation in carbonate rocks of fold-thrust belts of central Italy and eastern New York state. Unpublished Ph.D. dissertation, Columbia University.

Marshak, S. \& Engelder, T. 1985. Development of cleavage in limestones of a fold-thrust belt in eastern New York. J. Struct. Geol. 7 , 345-359.

Maxwell, D. T. \& Hower, J. 1967. High-grade diagenesis and lowgrade metamorphism of illite in the Precambrian Belt Series. Am. Miner. 52, 843-857.

Mitra, G. \& Yonkee, W. A. 1985. Relationship of spaced cleavage to folds and thrusts in the Idaho-Utah-Wyoming thrust belt. J. Struct. Geol. 7, 361-373

Nickelsen, R. P. 1972. Attributes of rock cleavage in some mudstones and limestones of the Valley and Ridge Province, Pennsylvania. Penn. Acad. Sci. 46, 107-112.

Oertel, G. 1983. The relationship of strain and preferred orientation of phyllosilicate grains in rocks-a review. Tectonophysics $\mathbf{1 0 0}$, 413-447.

Peacor, D. R., Essene, E. J. \& Lee, J. H. 1986. Investigation of the Stability of Clay/Basalt Packing Materials. Nuclear Regulatory Commission Publications, Washington, D.C.

Penoyar, S., Peacor, D. R., Lee, J. H. \& Wiltschko, D. V. 1983. Ordering in illites from the Pine Mountain thrust fault zone, Tennessee (abstr.). Trans. Am. geophys. Un. 64, 319.

Rickard, L. V. 1962. Late Cayugan (Upper Silurian) and Helderbergian (Lower Devonian) stratigraphy in New York. Bull. N.Y. State Mus. 386.

Schweitzer, J. \& Simpson, C. 1986. Cleavage development in dolomite of the Elbrook Formation, southwest Virginia. Bull. geol. Soc. Am. 97, 778-786.

Srodón, J. \& Eberl, D. D. 1984. Illite. In: Reviews in Mineralogy, Vol. 13, Micas (edited by Bailey, S. W.). Bookcrafters, Chelsea, 495517.

Weaver, C. E. \& Broekstra, B. R. 1984. Illite-mica. In: Shale-Slate Metamorphism in Southern Appalachians (edited by Weaver, C. E.). Elsevier, New York, 67-97.

Wenk, H. R., Barber, D. J. \& Reeder, R. J. 1983. Microstructures in carbonates. In: Reviews in Mineralogy, Vol. 11, Carbonates: Mineralogy and Chemistry (edited by Reeder, R. J, ). Bookcrafters, Chelsea, 301-367.

Weyl, P. K. 1959. Pressure solution and the force of crystallization-a phenomenological theory. J. geophys. Res, 64, 2001-2025.

Wood, D. S. 1974. Current views of the development of slaty cleavage. A. Rev. Earth Sci. 2, 369-401.

Yau, Y. C. \& Peacor, D. R. 1987. Smectite-illite reactions in Salton Sea shales: a transmission and analytical electron microscope study. J. Sedim. Petrol. 57, 335-342.

Yau, Y. C., Peacor, D. R., Essene, E. J., Lee, J. H., Kuo, L. C. \& Cosca, M. A. 1987. Hydrothermal treatment of smectite, illite, and basalt to $460^{\circ} \mathrm{C}$ : comparison of natural with hydrothermally formed clay minerals. Clays Clay Miner. 35. 241-250.

Yau, Y. C., Peacor, D. R., Beane, R. E., Essene, E. J. \& McDowell, S. D. In press. Microstructures, formation mechanisms and depthzoning of phyllosilicates in geothermally altered shales, Salton Sea, California. Clays Clay Miner.

Yoder, H. S. \& Eugster, H. P. 1955. Synthetic and natural muscovites. Geochim. cosmochim. Acta 8, 225-280.

Yonkee, W. A., Mitra, G. \& Frost, B. R. 1982. Relationship between mineral equilibria and deformation mechanisms during formation of solution cleavage (abstr.). Geol. Soc. Am. Abs. w. Prog. 14,651. 